\title{
High Temperature Raman Spectra of L-Leucine Crystals
}

\author{
P. F. Façanha Filho, P. T. C. Freire, K. C. V. Lima, J. Mendes Filho, F. E. A. Melo, \\ Departamento de Física, Universidade Federal do Ceará, \\ Campus do Pici, C.P. 6030 Fortaleza, CE, 60455-760, Brazil \\ and P. S. Pizani \\ Departamento de Física, Universidade Federal de São Carlos, São Carlos, SP, 13565-905, Brazil
}

Received on 30 October, 2007

\begin{abstract}
Single crystal samples of L-leucine, $\mathrm{C}_{6} \mathrm{H}_{13} \mathrm{NO}_{2}$, a fundamental aliphatic amino acid of the human body, have been studied by Raman spectroscopy at temperatures from 300 to $430 \mathrm{~K}$ over the spectral range from 50 to 3100 $\mathrm{cm}^{-1}$. A tentative assignment of all bands is given. For high temperatures, several modifications on the Raman spectra were observed at about $353 \mathrm{~K}$, giving evidence that the L-leucine crystal undergoes a structural phase transition. An interpretation for this phase transition in terms of group theory analysis is given.
\end{abstract}

Keywords: Leucine; Amino acid; Raman spectroscopy

\section{INTRODUCTION}

There has been a great deal of interest in the vibrational and structural characterization of amino acid crystals under extreme conditions in the last years. This interest has been fueled by the possibility of using them in technological devices, mainly in those cases where amino acid crystallizes together with other inorganic molecules, as occurs for L-arginine phosphate, which presents a high non-linear coefficient and can be used as a non-linear material involving several applications [1, 2]. Additionally, there are other aspects related to physical behavior that can be observed easily by vibrational and structural investigations. One of these aspects deals with the correlation among packing of molecules, the density and the stability of a certain crystal structure. For example, it is known that Lserine crystal is more dense than DL-serine, but the L-form undergoes a structural phase transition at lower pressure [3, 4]. In other words, the expected role played by the packing of molecules in the crystal is not so important, being more important for the problem the hydrogen bond interactions of the molecules.

Among the proteic amino acids the simplest are the aliphatic ones, compressing glycine (non-chiral), L-alanine, $\mathrm{L}$-isoleucine, L-valine and L-leucine. For the first three amino acids previous investigations do not shown any structural phase transition under temperature changes [5-8], although a study involving birrefrigence and light depolarization measurements have shown some symmetry breaking around 220 $\mathrm{K}$ for L-alanine [9]. It is also important to state that differently from the temperature change experiments, there is evidence that L-alanine undergoes a structural phase transition at about 2.2 GPa under high pressure conditions [10]. For the other two aliphatic amino acid crystals the picture is as follows. A temperature investigation on L-valine crystal using Raman spectroscopy technique showed that the material undergoes a phase transition between 100 and $120 \mathrm{~K}$ [11]. For L-leucine crystal, to the best of our knowledge, only Boygeard have published a work reporting properties of L-leucine crystal at high temperatures [12]. In such a work it was presented evidence of a phase transition at $80{ }^{\circ} \mathrm{C}$ through differential scanning calorimetry measurements and two unpolarized Raman spectra (at 300 and $360 \mathrm{~K}$ ) on L-leucine performed in the limited spectral range between 100 and $1700 \mathrm{~cm}^{-1}$.

The objective of this work is three-fold: (i) to present the Raman spectra of L-leucine crystal through the entire spectral range of the normal modes, $50-3200 \mathrm{~cm}^{-1}$, and give a tentative assignment of them; (ii) to present the temperature evolution of the Raman spectra of L-leucine crystal, giving particular attention to the changes which were associated to a structural phase transition undergone by the material; (iii) to give a tentative interpretation for the occurrence of this phase transition in terms of group theory analysis.

\section{EXPERIMENTAL}

Single crystals of L-leucine were grown from aqueous solution containing powder from Sigma by the slow evaporation method at controlled temperature. They were obtained as colorless tiny platelets, similarly with L-valine [11] and L-isoleucine [8] crystals. As occurs for L-isoleucine crystal, the large face (001) of the crystal is perpendicular to the $\mathrm{c}$-axis and this was defined as the z-axis through X-ray diffraction. The smaller faces have indices (100) and (110); the axis perpendicular to the (100) face is the $\mathrm{X}$-axis in our experiments. The backscattering light was analyzed using a Jobin Yvon Triplemate 64000 micro-Raman system equipped with an $\mathrm{N}_{2}$-cooled CCD detector. The slits were set for a $2 \mathrm{~cm}^{-1}$ spectral resolution. The excitation source for the Raman experiments was $514.5 \mathrm{~nm}$ radiation from an argon ion laser. In order to obtain high temperature a Linkan TS1500 micro furnace was utilized. The experiments were accomplished with heating of the sample and no crystal cracking was observed at the transition temperature.

\section{RESULTS AND DISCUSSION}

L-leucine (in the inset of Fig. 1 the molecular structure is shown) crystallizes in a monoclinic lattice belonging to 
the $P 2_{1}$ space group, $\beta=86.2^{\circ}$. The conformations of the two leucine molecules are similar but not identical to each other and to that in DL-leucine. According to Harding and Howieson [13], the carboxyl and amino groups are hydrogen bonded in a double layer very like that in other non-polar Lamino acids (for example, L-valine [11] and L-isoleucine [8]). In terms of the irreducible representations (IRep) of the $\mathrm{C}_{2}$ factor group, the normal modes are decomposed as $\Gamma=132 \mathrm{~A}$ $+132 \mathrm{~B}$, and because there are two acoustic modes at the $\mathrm{B}$ IRep and one at the A IRep, the optical modes are $\Gamma_{o p}=131$ $\mathrm{A}+130 \mathrm{~B}$.

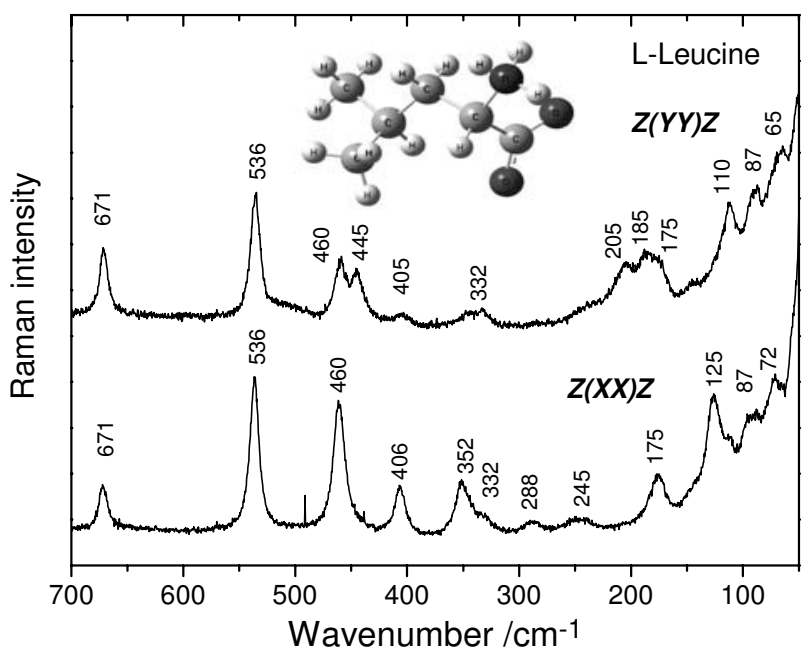

FIG. 1: Raman spectra of L-leucine crystal in the $50-700 \mathrm{~cm}^{-1}$ spectral region in the $\mathrm{z}(\mathrm{yy}) \mathrm{z}$ and $\mathrm{z}(\mathrm{xx}) \mathrm{z}$ scattering geometries. Inset: Molecular structure of L-leucine.

Figure 1 presents the Raman spectra of L-leucine crystals for two scattering geometries, $\mathrm{z}(\mathrm{yy}) \mathrm{z}$ and $\mathrm{z}(\mathrm{xx}) \mathrm{z}$, in the spectral region $50-700 \mathrm{~cm}^{-1}$. The axes were defined according to the following convention: the $\mathrm{z}$-axis was that perpendicular to the plane of the platelet and the $y$-axis was defined as the axis coincident with the longest dimension of the crystal; the $\mathrm{x}$-axis was defined perpendicular to the $\mathrm{y}$ - and $\mathrm{z}$-axes. In general terms, the bands observed with wavenumber lower than $150 \mathrm{~cm}^{-1}$ are associated to the lattice modes of the crystal (lat.) and they can give interesting insights about the stability of the structure under changes of thermodynamic parameter as temperature and pressure. The band at $175 \mathrm{~cm}^{-1}$ is tentatively associated to a torsion of $\mathrm{CO}_{2}^{-}$unit, $\tau\left(\mathrm{CO}_{2}^{-}\right)$, and bands at 185 and $205 \mathrm{~cm}^{-1}$, for the $\mathrm{z}(\mathrm{yy}) \mathrm{z}$ geometry, can be associated to torsions of $\mathrm{CH}, \tau(\mathrm{CH})$ [8]. In the L-leucine spectrum in the $\mathrm{z}(\mathrm{xx}) \mathrm{z}$ scattering geometry it is observed two bands at 245 and $288 \mathrm{~cm}^{-1}$ that can be associated with out-of-plane vibration of $\mathrm{CH}, \gamma(\mathrm{CH})$, and $\mathrm{CH}_{3}$ torsion, $\tau\left(\mathrm{CH}_{3}\right)$, respectively [14]. The low intense band at $332 \mathrm{~cm}^{-1}$ is tentatively assigned as a NCC deformation, $\delta$ (NCC) [11], while the bands at 352, 406, 445 and $460 \mathrm{~cm}^{-1}$ are assigned as skeletal structure deformations, $\delta$ (skel.) [14]. Finally, in the spectra of L-leucine presented in Fig. 1 it is observed an intense band at $536 \mathrm{~cm}^{-1}$ which is associated with the rocking of $\mathrm{CO}_{2}^{-}$unit, $\mathrm{r}_{\left(\mathrm{CO}_{2}^{-}\right)}$[8, 14]. It is interesting to note that the bands at 185,205 and $445 \mathrm{~cm}^{-1}$ are not observed in the spectrum of the $\mathrm{z}(\mathrm{xx}) \mathrm{z}$ scattering geometry. Also, in other spectral regions (see following figures) it is possible to observe that some bands are absent in the spectrum of one of the scattering geometries. This occurs because the orientation of the molecule allows that vibrations associated with molecular fragments could contribute with some Raman bands to a certain scattering geometry, while for others, such contribution is irrelevant.

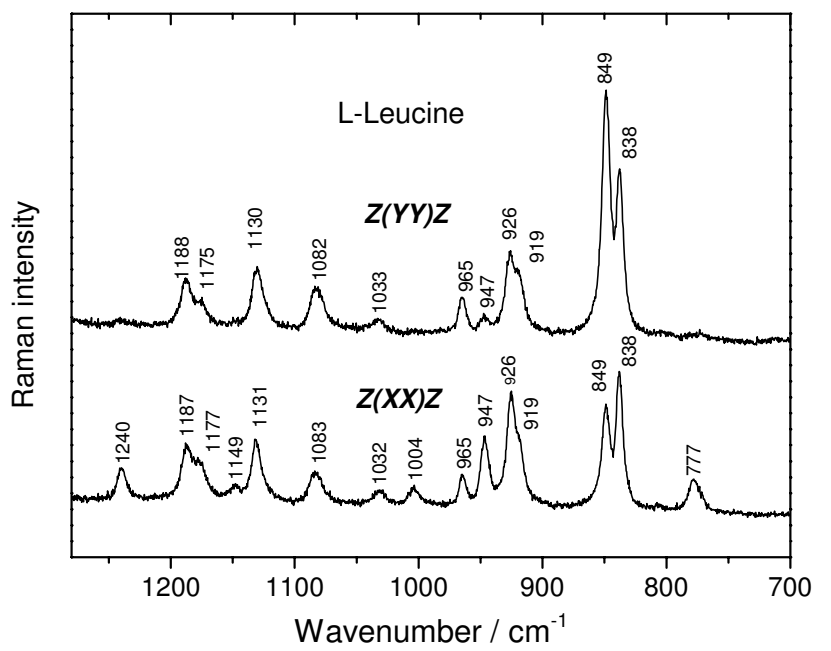

FIG. 2: Raman spectra of L-leucine crystal in the $700-1270 \mathrm{~cm}^{-1}$ spectral region in the $\mathrm{z}(\mathrm{yy}) \mathrm{z}$ and $\mathrm{z}(\mathrm{xx}) \mathrm{z}$ scattering geometries.

Figure 2 presents the Raman spectra of L-leucine in the spectral region $700-1270 \mathrm{~cm}^{-1}$. The band at $777 \mathrm{~cm}^{-1}$ is associated to a $\mathrm{CO}_{2}^{-}$deformation, $\delta\left(\mathrm{CO}_{2}^{-}\right)$[14]. The two bands at 838 and $849 \mathrm{~cm}^{-1}$ present an inversion of intensity for the two scattering geometries; they are assigned as out-ofplane vibration of $\mathrm{CO}_{2}^{-}, \gamma\left(\mathrm{CO}_{2}^{-}\right)$, and rocking of $\mathrm{CH}_{3}, \mathrm{r}\left(\mathrm{CH}_{3}\right)$ [8]. The $900-1100 \mathrm{~cm}^{-1}$ spectral region is characterized by bands associated to several $\mathrm{CC}$ and $\mathrm{CN}$ stretching vibrations, $v(\mathrm{CC})$ and $v(\mathrm{CN})[8,11]$. The band observed at $1131 \mathrm{~cm}^{-1}$ is assigned as rocking of $\mathrm{NH}_{3}^{+}$unit, $\mathrm{r}\left(\mathrm{NH}_{3}^{+}\right)$, as well as the doublet at 1177 and $1187 \mathrm{~cm}^{-1}$ (in the $\mathrm{z}(\mathrm{xx}) \mathrm{z}$ scattering geometry) [11]. The band at $1240 \mathrm{~cm}^{-1}$ is tentatively assigned as torsion of $\mathrm{CH}_{2}, \tau\left(\mathrm{CH}_{2}\right)$ [8].

The Raman spectra of L-leucine crystal in the $1280-1700$ $\mathrm{cm}^{-1}$ spectral region is presented in Fig. 3. This is a rich region, where many bands are observed, in particular, for the $\mathrm{z}(\mathrm{yy}) \mathrm{z}$ scattering geometry. Most of the bands in the region $1300-1375 \mathrm{~cm}^{-1}$ are assigned as deformations of $\mathrm{CH}$ unit, $\delta(\mathrm{CH})[8,12]$. Bands at 1391 and $1411 \mathrm{~cm}^{-1}$ are associated to symmetric bending of $\mathrm{CH}_{3}, \delta_{S}\left(\mathrm{CH}_{3}\right)$, and peaks at 1458 and $1475 \mathrm{~cm}^{-1}$ are associated to asymmetric bending of $\mathrm{CH}_{3}$, $\delta_{a}\left(\mathrm{CH}_{3}\right)$. In the $\mathrm{z}(\mathrm{yy}) \mathrm{z}$ scattering geometry the bands observed at 1560,1585 and $1626 \mathrm{~cm}^{-1}$ are associated to stretching vibrations of $\mathrm{CO}_{2}^{-}, \mathrm{vCO}_{2}^{-}$), and, possibly, to bending vibration of $\mathrm{NH}_{3}^{+}, \delta\left(\mathrm{NH}_{3}^{+}\right)[8,11,12]$. It is worthwhile to mention a particular remark related to the $1550-1650 \mathrm{~cm}^{-1}$ spectral region: observing the peaks appearing in the $\mathrm{z}(\mathrm{yy}) \mathrm{z}$ scat- 


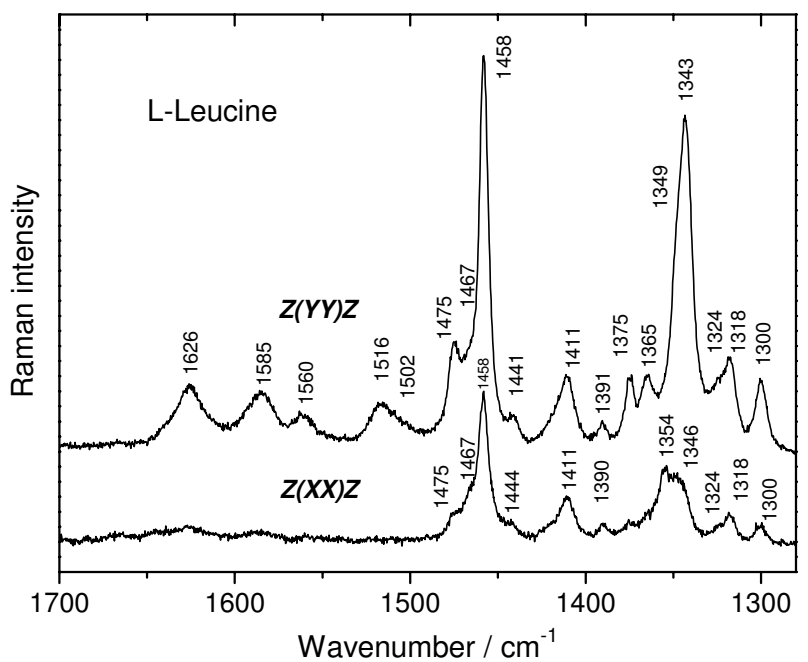

FIG. 3: Raman spectra of L-leucine crystal in the $1280-1700 \mathrm{~cm}^{-1}$ spectral region in the $\mathrm{z}(\mathrm{yy}) \mathrm{z}$ and $\mathrm{z}(\mathrm{xx}) \mathrm{z}$ scattering geometries.

tering geometry it is very clear that the band at $1626 \mathrm{~cm}^{-1}$ has an intensity greater than the band at $1585 \mathrm{~cm}^{-1}$ which is greater than the peak at $1560 \mathrm{~cm}^{-1}$. The observation of the same spectral region in L-valine [8] and L-isoleucine [11] reveals the same relationship of intensities for the three peaks. Additionally, the Raman spectrum of L-leucine presents no peak in this region for the $\mathrm{z}(\mathrm{xx}) \mathrm{z}$ scattering geometry; the same is true for L-valine [8] and L-isoleucine [11].

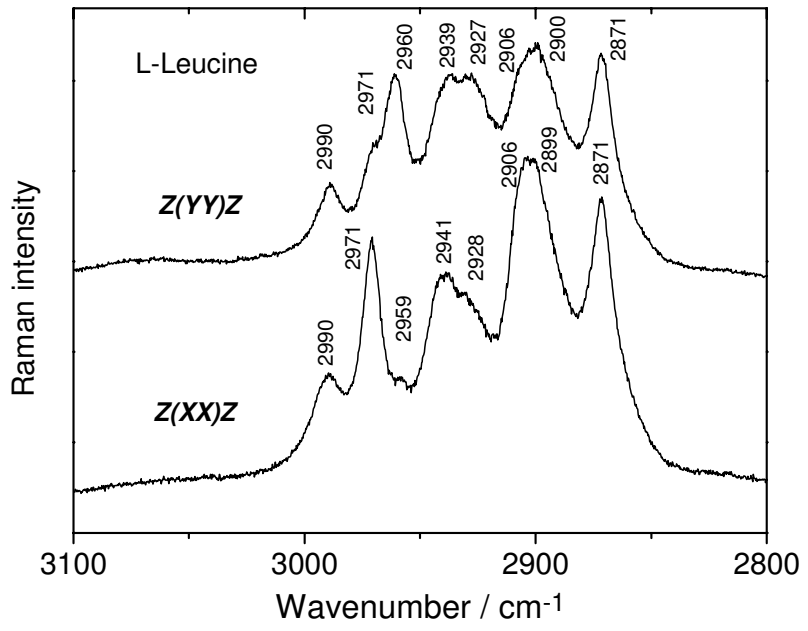

FIG. 4: Raman spectra of L-leucine crystal in the $2800-3100 \mathrm{~cm}^{-1}$ spectral region in the $\mathrm{z}(\mathrm{yy}) \mathrm{z}$ and $\mathrm{z}(\mathrm{xx}) \mathrm{z}$ scattering geometries.

Figure 4 presents the Raman spectra of L-leucine crystal for two scattering geometries in the $2800-3100 \mathrm{~cm}^{-1}$ spectral region. Bands due to the stretching vibrations of methylene, methyne and ammonium groups are expected to be observed in this high wavenumber region. However, as it is well known, the bands associated to the stretching vibrations of the $\mathrm{NH}_{3}$ group present low intensity in the Raman spectrum. In gen- eral, the other bands appear with wavenumbers very similar to those of L-isoleucine crystal; the tentative assignment of these bands is given in Table 1. A final observation is that no band was observed for wavenumber higher than $3100 \mathrm{~cm}^{-1}$, indicating that the crystal has grown as an anidrous form; in fact, when $\mathrm{OH}$ stretching vibrations are present, a large band centered at $\sim 3400 \mathrm{~cm}^{-1}$ is observed.

\section{HIGH-TEMPERATURE RAMAN SPECTRA}

The interest in the study of the vibrational properties of organic and semi-organic (an organic molecule with a nonorganic one, such as $\mathrm{HCl}$ or $\mathrm{H}_{2} \mathrm{O}$ ) substances varying temperature has grown in the last years mainly because of the possibility to shed light on the question of hydrogen bonds [15] and to help on the understanding of the phenomenon of polymorphism, mainly related to pharmaceuticals, pigments, and optical materials, among others [16]. Amino acid crystals, in particular, due to the fact that they are structures kept together through hydrogen and van der Waals bonds are expected to be unstable under great temperature variations. This is true, for example, for L-valine crystals that under lowtemperature conditions undergo a phase transitiona at about $100 \mathrm{~K}$ [11]. For L-isoleucine crystals, another aliphatic proteic amino acid, the same temperature changes verified in the L-valine experiment $(20-300 \mathrm{~K})$ do not affect the stability of the structure [8]. L-alanine crystal, the smallest chiral aliphatic amino acid, when submitted to the same temperature conditions, seems to maintain the orthorhombic roomtemperature structure, although the existence of a strong dynamic Jahn-Teller effect originated from the $\mathrm{NH}_{3}^{+}$chargelattice coupling would explain a previouly misterious lattice instability at $\sim 250 \mathrm{~K}$ [9]. Also, recently it was discovered that when L-alanine is fully deuterated, a structural phase transition is observed for temperature lower than $200 \mathrm{~K}$ [17].

In this section we discuss the effect of high temperature ( $\mathrm{T}$ $>297$ K) on the Raman spectra of L-leucine crystal. Fig. 5 shows the temperature evolution of the Raman spectra for all spectral regions in the $\mathrm{z}(\mathrm{yy}) \mathrm{z}$ scattering geometry. In order to facilitate the discussion we divided the spectra into four regions (Figs. 5(a) $-5(\mathrm{~d})$ ). Fig. 5(a) presents the bands appearing in the high-wavenumber region. The Raman spectra in this region show little changes, being observed only slight variations in the intensity of the bands. In fact, increasing temperature the two main effects on the $\mathrm{CH}_{2}$ and $\mathrm{CH}_{3}$ stretching region are: (i) a band at $2990 \mathrm{~cm}^{-1}$, initially well separated from the most intense bands of lower wavenumber decreases intensity and appears as a shoulder of the bands of 2960/ 2971 $\mathrm{cm}^{-1}$; (ii) bands at 2927 and $2939 \mathrm{~cm}^{-1}$, which are seen as a band with large linewidth in the room temperature spectrum, begins to be observed as distinct bands in the spectrum at 323 $\mathrm{K}$. For higher temperatures the two bands are clearly observed as separated ones.

Figure 5(b) presents the temperature evolution of the Raman spectra of L-leucine crystal for the $\mathrm{z}(\mathrm{yy}) \mathrm{z}$ scattering 
TABLE 1: Experimental wavenumbers from the Raman spectra of L-leucine crystal at room temperature and a tentative assignment of the modes.

\begin{tabular}{|c|c|c|c|c|c|}
\hline \multicolumn{3}{|c|}{ Raman } & \multicolumn{3}{|c|}{ Raman } \\
\hline $\mathrm{z}(\mathrm{xx}) \mathrm{z}$ & $z(y y) z$ & Assignment $^{\mathrm{a}}$ & $z(x x) z$ & $z(y y) z$ & Assignment $^{\mathrm{a}}$ \\
\hline $\begin{array}{c}\left(\mathrm{cm}^{-1}\right) \\
72\end{array}$ & $\begin{array}{c}\left(\mathrm{cm}^{-1}\right) \\
65\end{array}$ & lat. & $\begin{array}{c}\left(\mathrm{cm}^{-1}\right) \\
1149\end{array}$ & $\left(\mathrm{~cm}^{-1}\right)$ & \\
\hline 87 & 87 & lat. & 1177 & 1175 & $\mathrm{r}\left(\mathrm{NH}_{3}{ }^{+}\right)$ \\
\hline- & 110 & lat. & 1187 & 1188 & $\mathrm{r}\left(\mathrm{NH}_{3}^{+}\right)$ \\
\hline 125 & - & lat. & 1240 & - & $\tau\left(\mathrm{CH}_{2}\right)$ \\
\hline 175 & 175 & $\tau\left(\mathrm{CO}_{2}^{-}\right)$ & 1300 & 1300 & \\
\hline- & 185 & $\tau(\mathrm{CH})$ & 1318 & 1318 & \\
\hline- & 205 & $\tau(\mathrm{CH})$ & 1346 & 1343 & $\delta(\mathrm{CH})$ \\
\hline 245 & - & $\gamma(\mathrm{CH})$ & 1354 & 1351 & \\
\hline 288 & - & $\tau\left(\mathrm{CH}_{3}\right)$ & - & 1365 & \\
\hline 332 & 332 & $\delta(\mathrm{NCC})$ & - & 1375 & \\
\hline 352 & - & $\delta$ (skel.) & 1390 & 1391 & $\delta_{\mathrm{s}}\left(\mathrm{CH}_{3}\right)$ \\
\hline 406 & 405 & $\delta$ (skel.) & 1411 & 1411 & $\delta_{\mathrm{s}}\left(\mathrm{CH}_{3}\right)$ \\
\hline- & 445 & $\delta$ (skel.) & 1444 & 1441 & - \\
\hline 460 & 460 & $\delta$ (skel.) & 1458 & 1458 & $\delta_{\mathrm{a}}\left(\mathrm{CH}_{3}\right)$ \\
\hline 536 & 536 & $\mathrm{r}\left(\mathrm{CO}_{2}^{-}\right)$ & 1475 & 1475 & $\delta_{a}\left(\mathrm{CH}_{3}\right)$ \\
\hline 671 & 671 & $\mathrm{w}\left(\mathrm{CO}_{2}^{-}\right)$ & - & 1516 & - \\
\hline 777 & - & $\delta\left(\mathrm{CO}_{2}^{-}\right)$ & - & 1560 & $\mathrm{v}\left(\mathrm{CO}_{2}^{-}\right)$ \\
\hline 838 & 838 & $\gamma\left(\mathrm{CO}_{2}^{-}\right)$ & - & 1585 & $v\left(\mathrm{CO}_{2}^{-}\right)$ \\
\hline 849 & 849 & $\mathrm{r}\left(\mathrm{CH}_{3}\right)$ & - & 1626 & $\mathrm{v}\left(\mathrm{CO}_{2}^{-}\right)$ \\
\hline 919 & 919 & $v(C C)$ & 2871 & 2871 & $v_{\mathrm{s}}\left(\mathrm{CH}_{3}\right)$ \\
\hline 926 & 926 & $v(\mathrm{CC})$ & 2899 & 2900 & $\mathrm{v}_{\mathrm{s}}\left(\mathrm{CH}_{3}\right)$ \\
\hline 947 & 947 & $v(C C)$ & 2906 & 2906 & $v\left(\mathrm{CH}_{2}\right)$ \\
\hline 965 & 965 & $v(\mathrm{CC})$ & 2928 & 2927 & $\mathrm{v}\left(\mathrm{CH}_{2}\right)$ \\
\hline 1004 & - & $v(\mathrm{CC})$ & 2941 & 2939 & $\mathrm{v}(\mathrm{CH})$ \\
\hline 1032 & 1033 & $v(\mathrm{CN})$ & 2959 & 2960 & $\mathrm{v}(\mathrm{CH})$ \\
\hline 1083 & 1082 & $v(\mathrm{CN})$ & 2971 & 2971 & $\mathrm{v}_{\mathrm{a}}\left(\mathrm{CH}_{3}\right)$ \\
\hline 1131 & 1131 & $\mathrm{r}\left(\mathrm{NH}_{3}{ }^{+}\right)$ & 2990 & 2990 & $\mathrm{~V}_{\mathrm{a}}\left(\mathrm{CH}_{3}\right)$ \\
\hline
\end{tabular}

${ }^{a}$ lat., lattice vibration; $\tau$, torsion; $\delta$, bending; r, rocking; w, wagging; $\gamma$, out-of-plane vibration; $v$, stretching; skel., skeletal vibration; s, symmetric; a, asymmetric.

geometry in the spectral region $1280-1750 \mathrm{~cm}^{-1}$. Here, several aspects can be cited. First, most of the bands decrease intensity as occurs for the band observed at $1300 \mathrm{~cm}^{-1}$ in the spectrum of room temperature. However, for the doublet 1318 and $1324 \mathrm{~cm}^{-1}$ an interesting effect is observed: by increasing temperature the low-intensity band at $1324 \mathrm{~cm}^{-1}$ decreases intensity in such a way that in the spectra of $323-343 \mathrm{~K}$ it is observed only as a shoulder of the other band. In the spectrum taken at $353 \mathrm{~K}$ the band originally at $1324 \mathrm{~cm}^{-1}$ is not visible and, at the same time, the neighboring band (originally at $1318 \mathrm{~cm}^{-1}$ ) seems to increase intensity relatively to the other bands of the spectrum. A possible explanation for this not conventional fact is that starting from the $353 \mathrm{~K}$, the doublet becomes degenerated.

The low-intensity bands observed in the room temperature spectrum at 1365 and at $1441 \mathrm{~cm}^{-1}$ are seen only as shoulders of the intense neighboring bands (at 1343 and $1458 \mathrm{~cm}^{-1}$, respectively) when the sample is heated up to $393 \mathrm{~K}$. Another observation in the spectra of Fig. 5(b) refers to the bands between 1550 and $1650 \mathrm{~cm}^{-1}$. The band observed originally at $1560 \mathrm{~cm}^{-1}$ has its intensity vanishing for $\mathrm{T}=353 \mathrm{~K}$. Also, the bands at 1585 and $1626 \mathrm{~cm}^{-1}$ change intensities when temper- ature varies from 297 to $413 \mathrm{~K}$, similarly to what occurs with low-wavenumber bands of L-valine crystal at low temperature [11] and with low-wavenumber bands of L-alanine crystal at high pressure conditions [10]. While for low-wavenumber peaks, which are associated to lattice modes of amino acid molecule, the change of intensities are ascribed to a mutual molecular reorientation in the lattice, for these modes of highwavenumber we believe that the relative change of intensities could be attributed to coupling of internal modes with modes of low energy or to different temperature variation of intensities, giving rise to an apparent exchange of intensities.

Figure 5(c) shows the temperature evolution of the Raman spectra of L-leucine crystal for the $\mathrm{z}(\mathrm{yy}) \mathrm{z}$ scattering geometry in the spectral region $700-1250 \mathrm{~cm}^{-1}$. One interesting aspect is worth mentioning. A band at $\sim 810 \mathrm{~cm}^{-1}$ begins to be observed when temperature reaches $353 \mathrm{~K}$, i.e., at room temperature there is no band between 700 and $830 \mathrm{~cm}^{-1}$ and at that temperature a band appears. Also interesting is the fact that at room temperature it is observed a doublet at 919 and $926 \mathrm{~cm}^{-1}$; when the sample is heated the bands lose intensity but remain as two distinct bands up to $343 \mathrm{~K}$. However, when the L-leucine crystal is submitted to a temperature of $353 \mathrm{~K}$ 


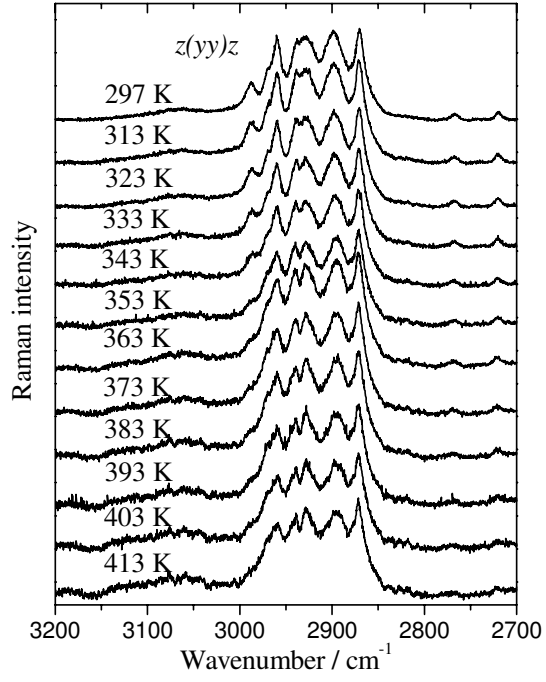

(a)

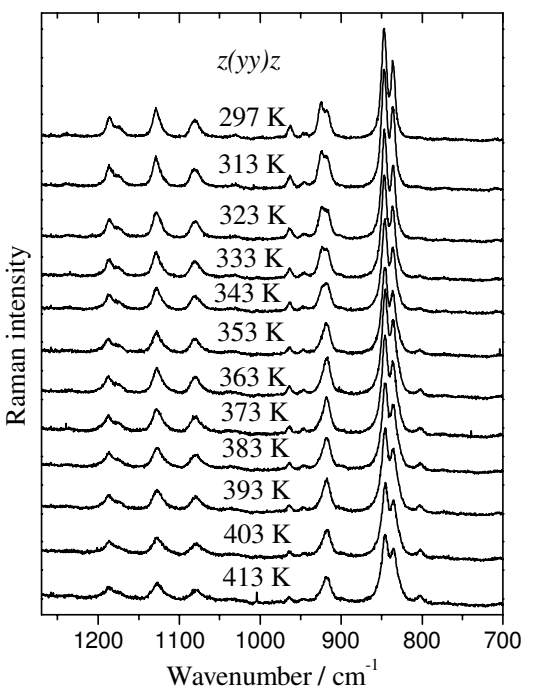

(c)

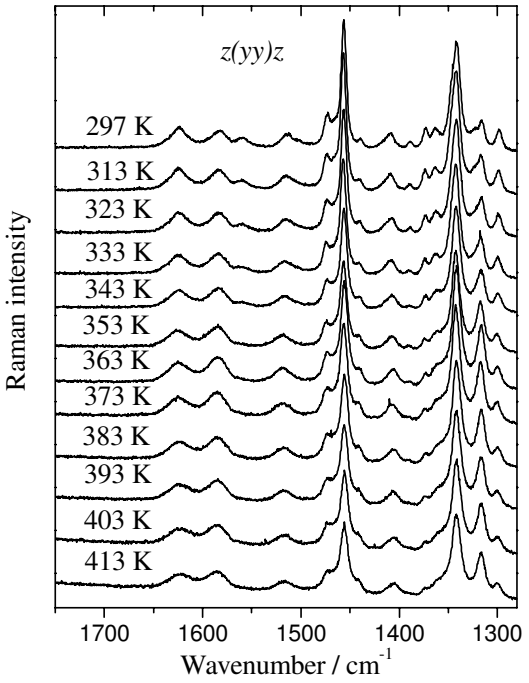

(b)

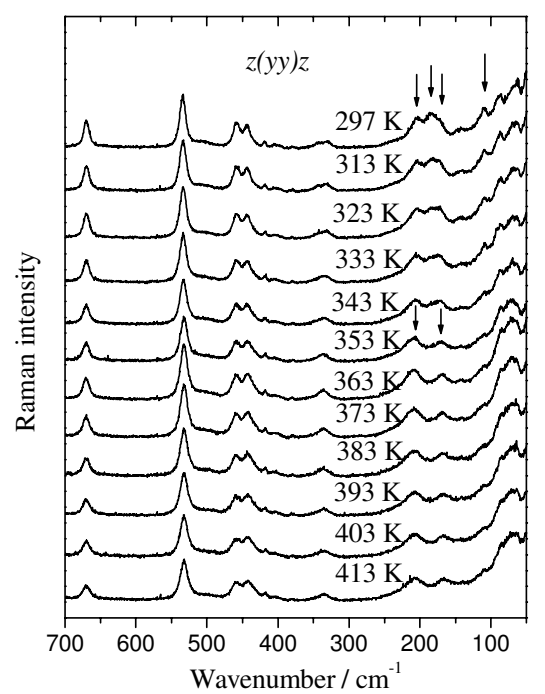

(d)

FIG. 5: Raman spectra of L-leucine crystal in the $50-3200 \mathrm{~cm}^{-1}$ spectral region in the $\mathrm{z}(\mathrm{yy}) \mathrm{z}$ scattering geometry for several temperatures.

the doublet originates one only band.

Figure 5(d) presents the Raman spectra of L-leucine crystals for the $\mathrm{z}(\mathrm{yy}) \mathrm{z}$ scattering geometry in the region $50-700$ $\mathrm{cm}^{-1}$ for several temperatures. In the region $300-700 \mathrm{~cm}^{-1}$ it is observed that all bands decrease intensities and their linewidths increase, as one expects. Bands at 175, 185 and $205 \mathrm{~cm}^{-1}$ (marked by three down arrows), associated to torsional modes, are well visible in the spectrum at room temperature but, when temperature is increased, one observes that the band originally at $185 \mathrm{~cm}^{-1}$ decreases intensity in such a way that at $353 \mathrm{~K}$ only two bands are present (they are marked by two arrows). The two bands remain up to the highest temperature of the experiments.

The region of the external modes (wavenumbers up to $\sim$ $150 \mathrm{~cm}^{-1}$ ), in particular, deserves special attention. We have shown that at $\sim 353 \mathrm{~K}$ a series of changes appears in the internal modes region of L-leucine crystal. This can be an indication that some change in the structure is taking place at that temperature, although other phenomena can explain changes in bands associated to internal mode vibrations. One of the most known examples is related to L-alanine crystal where the splitting of the $\mathrm{NH}_{3}^{+}$torsional mode is observed at $\sim 220$ $\mathrm{K}$, but being associated to small distortions of the $\mathrm{NH}_{3}^{+}$group, not to a structural phase transition [6]. On the contrary, taurine crystal is an example where changes in bands associated to internal modes (e.g. torsional vibration of CSH moiety) are effectively related to a structural modification [18]. For Lleucine crystal one observes that at $\mathrm{T}=297 \mathrm{~K}$ three different bands (up to $150 \mathrm{~cm}^{-1}$ ) are present in the spectrum. When the sample is heated the evolution of the two bands of lowest 
energy is such that at the highest temperature they appear as a large band. The most important effect, however, is observed for the band at $110 \mathrm{~cm}^{-1}$, also marked by an arrow: its intensity continuously decreases and at about $353 \mathrm{~K}$ it goes to zero. The vanishing of this band associated to a lattice vibration can in a straightforward way be interpreted as a structural phase transition undergone by L-leucine crystal at $353 \mathrm{~K}$.

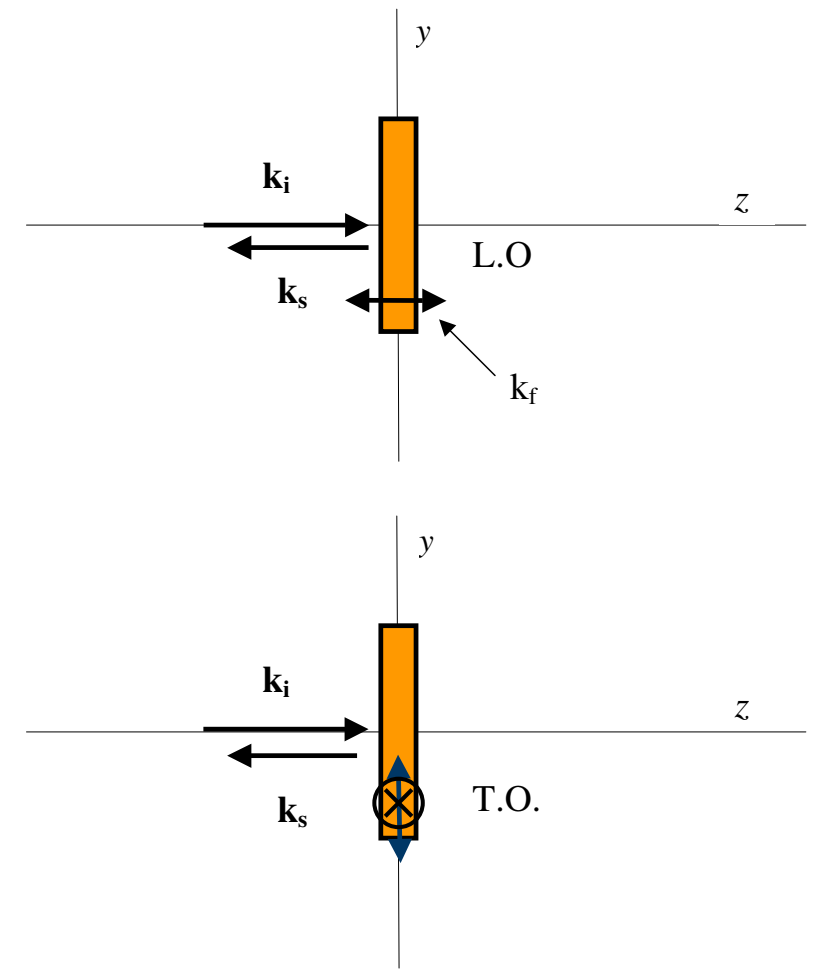

FIG. 6: Representations of the L-leucine crystal in the yz plane; $\mathbf{k}_{i}$, $\mathbf{k}_{s}$ and $\mathbf{k}_{f}$ stand, respectively, for the wave vector of incident and scattered lights and for the wave vector of the phonons. The upper representation corresponds to the $\mathrm{C}_{2}$ symmetry of the room temperature phase: the polarization of the phonon is in the same direction of $\mathbf{k}_{f}$. The lower representation corresponds to the $\mathrm{C}_{s}$ symmetry of the high temperature phase: $\mathbf{k}_{f}$ is in the $\mathrm{z}$ direction (not represented, for simplicity) and polarizations are in the $\mathrm{x}$ and $\mathrm{y}$ directions.

A possible interpretation for this phase transition is given as follows: at room temperature the crystal belongs to a $\mathrm{C}_{2}$ symmetry and above $353 \mathrm{~K}$ the crystal belongs to a $\mathrm{C}_{s}$ symmetry. In this way, when the temperature is increased close to the phase transition, longitudinal optical (LO) modes begin to decrease intensity and in the new phase the intensity goes to zero. This explains the disappearance of modes of low energy, as well as, those around $920 \mathrm{~cm}^{-1}$. Fig. 6 shows a representation of the crystal in the yz plane for the room temperature phase (upper) and for the high temperature phase (lower) with the wave vectors for the incident $\left(\mathbf{k}_{i}\right)$ and scattered $\left(\mathbf{k}_{s}\right)$ lights and the wave vector for the phonons $\left(\mathbf{k}_{f}\right)$.
The incident and scattered lights are in the $\mathrm{z}$ direction and the phonons involved are in the same direction. Through the character table of $\mathrm{C}_{2}$ group (Ref. [19]) it is clear that only phonons with z-polarization are allowed and, as a consequence, the modes involved in the scattering process at room temperature are LO. Above $353 \mathrm{~K}$ (supposing the new symmetry being $\mathrm{C}_{S}$ ) the phonons propagating in the z-direction are polarized in the $\mathrm{x}$ and $\mathrm{y}$ directions [19] and, consequently, the phonons involved in the scattering process are transversal optical (TO) modes.

As pointed out in Ref. [20], the molecules of L-leucine in the unit cell are organized in layers parallel to the $b c$ face of the crystal. These layers present two kinds of interactions: on one side they interact via hydrogen bonds and on the other side they interact through the methyl groups of the leucine side chains. Because we have observed changes in the lowwavenumber region, it is possible that the phase transition involves the rupture of one hydrogen bond among the three possibilities of $\mathrm{H}$ bonds on amino $\mathrm{N}$ atoms with different molecules. The understanding of this dynamics which must be achieved by other measurements (X-ray and neutron diffractions) will be important to shed light on the interactions of alternating polypeptides that have similar organization to those of L-leucine molecules in their crystalline structure.

\section{CONCLUSIONS}

Raman spectra of L-leucine crystal were investigated for the interval $50-3100 \mathrm{~cm}^{-1}$ (for wavenumbers higher than $3100 \mathrm{~cm}^{-1}$ and up to $3600 \mathrm{~cm}^{-1}$ no band was observed) and a tentative assignment of the modes was given. The temperature evolution of the Raman spectra showed a series of modifications in the internal mode region at about $353 \mathrm{~K}$. In this same temperature changes in the external mode region furnished evidence for a structural phase transition undergone by L-leucine crystal. A change of symmetry from the $\mathrm{C}_{2}$ to the $\mathrm{C}_{s}$ point group through the appearance of TO modes at high temperatures is suggested to explain the mechanism of the phase transition. This physical observation puts L-leucine in the same class of L-valine crystal among the aliphatic amino acid crystals which present at least one type of structural change. In another class it is possible to find L-alanine [6], D-alanine [21], D-valine [22] and L-isoleucine [8], which are stable under a very large range of temperature (at least for low-temperature conditions).

\section{ACKNOWLEDGEMENTS}

We thank Dr. J. Ramos Gonçalves for a critical reading of the manuscript. Financial support from FUNCAP and CNPq is gratefully acknowledged.
[1] S.B. Monaco, L.E. Davis, S.P. Velsko, F.T. Wang, D. Eimerl, and A. Zalkin, J. Cryst. Growth 85, 252 (1987).
[2] D. Eimerl, S. Velsko, L. Davis, F. Wang, G. Loiacono, and G. 
Kennedy, IEEE J. Quantum Electron. 25, 179 (1989).

[3] E.N. Kolesnik, S.V. Goryainov, and E.V. Boldyreva, Dokl. Phys. Chem. 404, 169 (2005).

[4] S.A. Moggach, D.R. Allan, C.A. Morrison, S. Parsons, and L. Sawyer, Acta Crystallogr. B 61, 58 (2005).

[5] C. Murli, S. Thomas, S. Venkateswaran, and S.M. Sharma, Physica B. 364, 233 (2005)

[6] M. Barthes, H.N. Bordallo, F. Dénoyer, J.-E. Lorenzo, J. Zaccaro, A. Robert, and F. Zontone, Eur. Phys. J. B 37, 375 (2004).

[7] M.S. Lehmann, T.F. Koetzle, and W.C. Hamilton, J. Am. Chem. Soc. 94, 2657 (1972).

[8] F.M. Almeida, P.T.C. Freire, R.J.C. Lima, C.M.R. Remédios, J. Mendes, and F.E.A. Melo, J. Raman Spectrosc. 37, 1296 (2006).

[9] M. Barthes, A.F. Vik, A. Spire, H.N. Bordallo, and J. Eckert, J. Phys. Chem. A 106, 5230 (2002).

[10] A.M.R. Teixeira, P.T.C. Freire, A.J.D. Moreno, J.M. Sasaki, A.P. Ayala, J. Mendes, and F.E.A. Melo, Solid State Commun. 116, 405 (2000).

[11] J.A. Lima, P.T.C. Freire, R.J.C. Lima, A.J.D. Moreno, J. Mendes, and F.E.A. Melo, J. Raman Spectrosc. 36, 1076 (2005).
[12] D. Bougeard, Ber. Bunsen-Ges. Phys. Chem, Chem. Phys. 87, 279 (1983).

[13] M.M. Harding, R.M. Howieson, Acta Cryst. B 32, 633 (1976).

[14] A. Pawlukojc, J. Leciejewicz, and I. Natkaniec, Spectroc. Acta A 52, 29 (1996).

[15] G.A. Jeffrey, An Introduction to Hydrogen Bonding, Oxford University Press, New York, 1997.

[16] J. Bernstein, Polymorphism in Molecular Crystals, Oxford University Press, Oxford, 2002.

[17] J.M. Souza, P.T.C. Freire, H.N. Bordallo, and D.N. Argyriou, J. Phys. Chem. B 111, 5034 (2007).

[18] R.J.C. Lima, P.T.C. Freire, J.M.Sasaki, F.E.A. Melo, J. Mendes, and R.L. Moreira, J. Raman Spectrosc. 32, 751 (2001).

[19] D.L. Rousseau, R.P. Bauman, and S.P.S. Porto, J. Raman Spectrosc. 10, 253 (1981).

[20] M. Coll, X. Solans, M. Font-Altaba, and J.A. Subirana, Acta Cryst. C42, 599 (1986).

[21] C.C. Wilson, D. Myles, M. Ghosh, L.N. Johnson, and W. Wang, New J. Chem. 29, 1318 (2005)

[22] W.Q. Wang, Y. Gong, Z.M. Wang, and C.H. Yan, J. Struct. Chem. 22, 539 (2003). 